\title{
Estudos geográficos sobre a Antártica: geopolítica, solos, relevo e clima.
}

\section{Geographic studies on Antarctica: geopolitics, soils, relief and climate.}

\author{
Daví do Vale Lopes ${ }^{1}$; Fabio Soares de Oliveira ${ }^{2}$; José João Lelis Leal de Souza ${ }^{3}$; Carlos \\ Ernesto G.R. Schaefer ${ }^{4}$
}

\begin{abstract}
RESUMO: Este trabalho tem como objetivo compartilhar informações e reflexões sobre as pesquisas científicas geográficas realizadas na Antártica. A abordagem está fundamentada na visão de geógrafos que realizaram expedições antárticas como membros do Núcleo de Pesquisas Terrantar/UFV. Abordou-se sobre algumas possibilidades de regionalização da Antártica. Apesar de ser um território internacional destinado a paz e ciência, existem disputas geopolíticas. Os estudos sobre Geomorfologia possibilitam o monitoramento da dinâmica dos glaciares e que se faça reconstruções paleoambientais. Informações sobre os solos são importantes para registros de contaminações ambientais, monitoramento do permafrost, e auxílio na interpretação das paisagens exuberantes e cheias de mistérios. Análises climáticas nas sensíveis paisagens Antárticas são relevantes para melhor compreensão das mudanças climáticas. Massas de ar e correntes marítimas oriundas do continente influenciam nos regimes térmicos e precipitações na América do Sul. Estes conteúdos tem grande potencialidade de utilização no ensino de Geografia, podendo tornar as aulas mais atrativas e estimulantes.
\end{abstract}

PALAVRAS-CHAVE: Geopolítica Antártica; permafrost; geleiras.

\begin{abstract}
The purpose of this study was to share informations and reflections on how geographic scientific research carried out in Antarctica. This approach is based on the viewpoint of geographers who carry out Antarctic expeditions as members of the Terrantar Research Center/UFV. Antarctica has several possibilities for regionalization. Despite being an international territory destined for peace and science, there are geopolitical disputes. Studies on geomorphology make it possible to monitor glaciers and make paleoenvironmental reconstructions. Soil information is important for recording environmental contamination, monitoring permafrost, and helping to interpret lush and mysterious landscapes. Climate studies in Antarctica are important for climate change issues. Oceanic and atmospheric coupling between Antarctic and South America may lead to change precipitation and temperatures if global warming persists. Explore the geography of Antarctica has potential to be used in the teaching of Geography, which can be useful to attract students' attention and interest.
\end{abstract}

1 Dr. em Geografia pela UFMG. ORCID id: 0000-0003-3336-7397. E-mail: davivlopes@hotmail.com

${ }^{2}$ Prof. Dr. da UFMG. E-mail: fabiosolos@gmail.com

${ }^{3}$ Prof. Dr. da UFV. ORCID id: 0000-0003-4670-6626. E-mail: jjlelis@ gmail.com

${ }^{4}$ Prof. Dr. da UFV. ORCID id: 0000-0001-7060-1598. E-mail: carlos.schaefer@ufv.br 
KEYWORDS: Antarctic geopolitics; permafrost; glaciers.

\section{INTRODUÇÃO.}

O termo Antártica vem de Anti-Ártico, ou seja, lado oposto no globo terrestre. No senso comum a Antártica (ou Antártida) é conhecida como o continente dos superlativos: mais inóspito, mais alto, mais frio, mais ventoso, mais seco e mais desértico (CAMPBELL; CLARIDGE, 1987; LOPES et al., 2017; ANDRADE et al., 2018). É o quinto maior continente do mundo, área de 14 milhões de $\mathrm{km}^{2}$ (área 1,6 vezes maior do que o território brasileiro) completamente cercado pelo Oceano Austral (Figura 1). A espessura média de gelo é de aproximadamente $2100 \mathrm{~m}$, o que representa cerca de 90\% do volume total de gelo do mundo (importante reserva de água doce) (CAMPBELL; CLARIDGE, 1987).

Figura 1: Mapa de localização da Antártica em relação aos continentes vizinhos (Ámérica, África e Oceania).

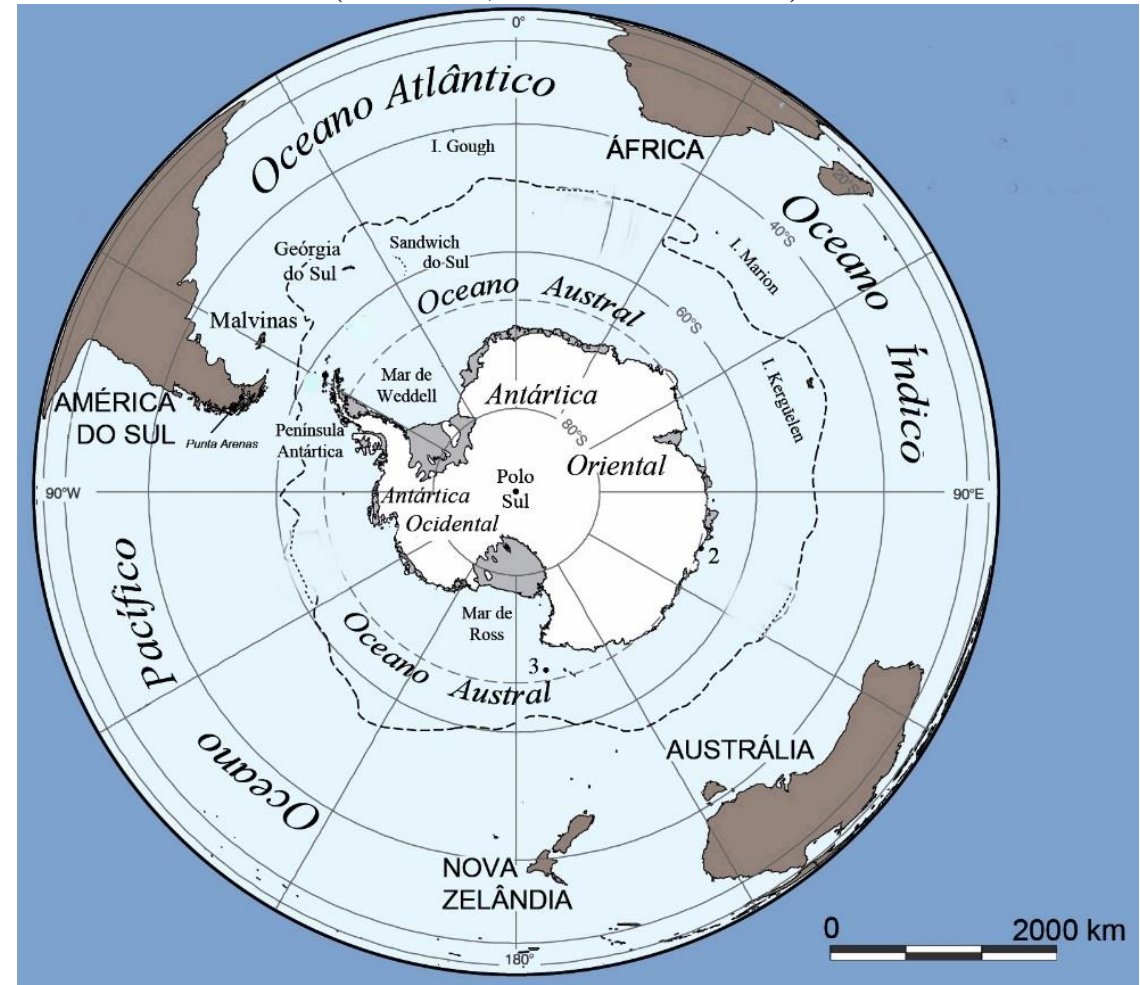

Fonte: Simões (2011).

A Antártica é um continente diverso e suas condições climáticas são distintas no território. Apenas 2\% da Antártica é livre de gelo (CAMPBELL; CLARIDGE, 1987). Para Bockheim (2015), esse valor perfaz apenas 0,35\% do continente, ou 45 mil $\mathrm{Km}^{2}$ (Figura 2.A). A região denominada Antártica Marítima, que compreende a Península 
Antártica e arquipélagos adjacentes, apresenta uma das maiores áreas livres de gelo (Figura 2.B), clima menos severo, temperaturas mais elevadas e maiores índices precipitação líquida.

Figura 2: A - Mapa da Antártica representando as poucas áreas livres de gelo (rocha exposta), dominância de mantos de gelo (massa de gelo glaciar que cobre uma superfície terrestre) e plataformas de gelo (massa de gelo espessa e flutuante); B Arquipélago Shetland do Sul com indicação das principais ilhas; C - Abertura de entrada na Ilha Deception (Ilha que possui formato semicircular); D - Ilha Rei George, onde localiza-se a base de pesquisa do Brasil.

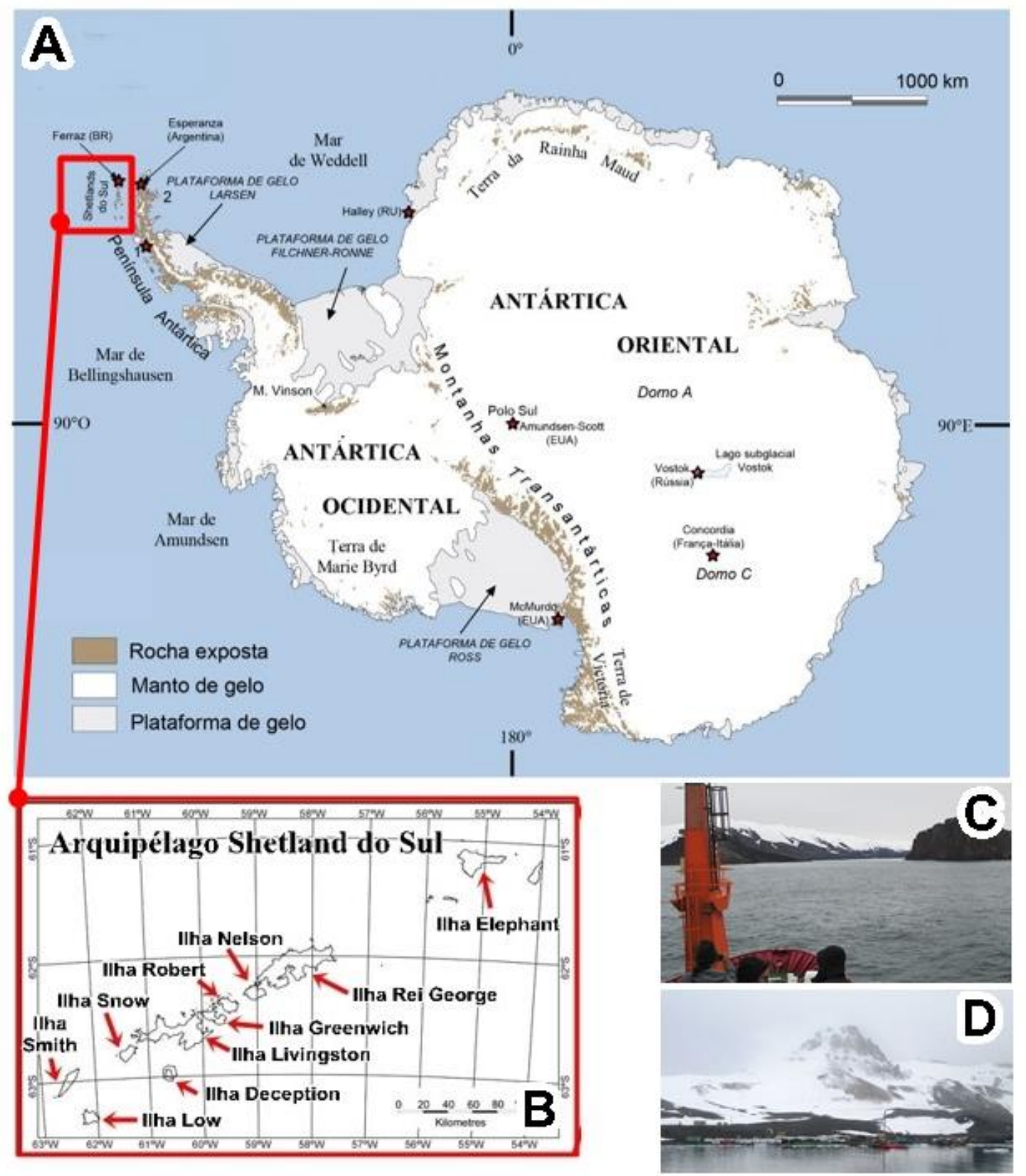

Fonte: Esquema elaborado pelos autores. Fotos de arquivo pessoal e mapas adaptados de Simões, Arigony-Neto e Bremer (2004) e Simões (2011). 
Desde 2002 o Núcleo Terrantar (ligado ao Instituto Nacional de Ciência e Tecnologia da Criosfera), com sede na Universidade Federal de Viçosa (UFV), vem atuando na Antártica em parcerias com diversas instituições e pesquisadores do Brasil e exterior. O Terrantar vem trabalhando com avanços e desafios em estudos do permafrost, questões climáticas associadas e interfaces entre solo-vegetação-relevo (SIMAS et al., 2006; MICHEL et al., 2006; SIMAS et al., 2007; FRANCELINO et al., 2011; PEREIRA et al., 2013; ALMEIDA et al., 2014; DELPUPO et al, 2014; SIMAS et al., 2015; LOPES et al., 2017; LOPES et al., 2019). Nesta perspectiva muitos geógrafos fizeram expedições para Antártica e ofereceram muitas contribuições científicas, trazendo novas informações e permitindo a maior divulgação do território tão longínquo, inóspito e com características singulares.

Este trabalho teve como objetivo compartilhar informações e reflexões sobre as pesquisas científicas de cunho geográfico realizadas na Antártica, as quais despertam muito interesse e curiosidade, tendo grande potencialidade de utilização no processo de ensino/aprendizagem.

\section{GEOPOLÍTICA, TRATADO ANTÁRTICO E BASES DE PESQUISAS.}

Ao longo dos séculos XVIII e XIX a Antártica ficou restrita à ação de baleeiros e caçadores de focas, atendendo às necessidades de graxa, azeite e peles dos países europeus (GANDRA, 2009). Até hoje em várias partes da Antártica observa-se resquícios destas atividades, destaca-se na Ilha Deception (Figura 2.B), a Baía dos Baleeiros, a qual possui marcos descritivos da ocupação histórica da área. A baía foi ocupada por noruegueses em 1911, onde foi construída uma planta para extração do óleo de baleia, o colapso do preço do produto levou ao encerramento das atividades em 1931. Os edifícios abandonados foram ocupados pela Marinha Britânica em 1944 e no ano seguinte converteu-se em um centro de pesquisas. Esta área é um ponto turístico, destino de cruzeiros que vão para Antártica (Figura 3.C). 
Figura 3: Atividades humanas e paisagens antárticas. A - avião Hércules da FAB na pista de pouso da base aérea chilena Presidente Eduardo Frei Montalva na Ilha Rei George; B: Iceberg próximo à Península Antártica; C - turistas na Ilha Deception; D: Reconstrução da estação de pesquisa do Brasil na Ilha Rei George (registro em 2017); E: Colônia de pinguins em Hope Bay, Península Antártica; F - coleta de solos na Ilha Snow, pesquisadores tem o cuidado de retirar o tapete de musgos e recolocá-los no local de origem após as coletas, com o intuito de minimizar os impactos.

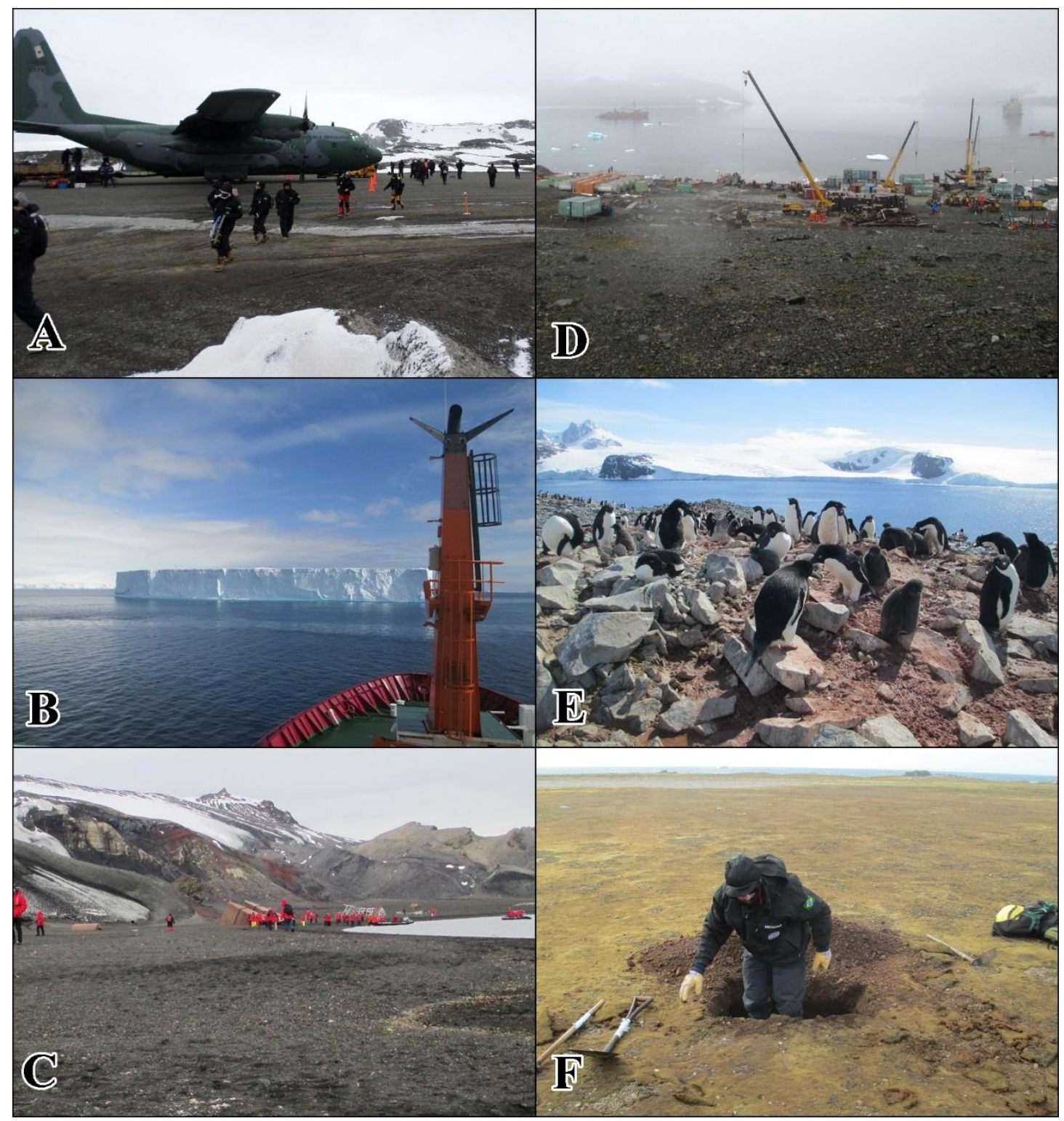

Fonte: Arquivo pessoal.

As atividades de caça e pesca predatória no continente foram encerradas a partir da assinatura do Tratado Antártico (1959). Este acordo "colocou em pausa" todas as reivindicações territoriais que existiam, entre estas destaca-se as rivalidades históricas entre Argentina e Chile, únicos países latino-americanos que participaram da elaboração das diretrizes jurídicas do Tratado (GANDRA, 2009). 
O Tratado Antártico entrou em vigor em 1961 e determinou que o continente fosse um território pacífico internacional, reservado a atividades cientificas. Neste momento, o mundo vivia um contexto de Guerra Fria e as grandes potências mundiais, EUA e URSS, tinham outras prioridades de expansões territoriais, em detrimento da inóspita, longínqua e "desconhecida" Antártica.

O Tratado foi assinado com prazo de validade, 2048, até lá a única forma de marcar território no continente é através da instalação de bases de pesquisas científicas, as quais estão espalhadas por várias partes, demonstrando os interesses geopolíticos na região. A maior estação de pesquisa da Antártica, pertence aos EUA, denominada McMurdo, e o país com o maior número de estações permanentes é a Rússia, com sete estações (ANDRADE et al., 2018).

A base de pesquisa do Brasil é denominada Estação Antártica Comandante Ferraz (EACF), edificada em 1984 na Ilha Rei George (Figuras 2.B e 2.D). O Brasil aderiu ao Tratado em 1975, em plena Ditadura Militar, o então presidente do país era Ernesto Geisel. Este contexto, era marcado pelas ideias ufanista do "Brasil Grande", assim, abriu-se as portas para a ciência brasileira participar de atividades na Antártica, junto com a comunidade científica internacional (GANDRA, 2009).

As expedições científicas brasileiras para o continente são regidas seguindo os procedimentos estabelecidos pelo Programa Antártico Brasileiro (PROANTAR). O PROANTAR foi instituído em 1982, desde então está a cargo da Comissão Interministerial para os Recursos do Mar (CIRM), órgão vinculado ao Ministério da Marinha. A presença na Antártica, do ponto de vista militar, se resume em um objetivo territorial, uma questão de segurança nacional (GANDRA, 2009; ANDRADE et al., 2018).

Todos os cientistas brasileiros que vão para Antártica são submetidos a um treinamento prévio (denominado Treinamento Pré-Antártico, sigla TPA), com testes físicos, exames médicos, aprendizados básicos de sobrevivências, noções básicas sobre acampamento e repasse de uma série de informações sobre o continente e suas particularidades. Estas atividades são controladas pela Marinha do Brasil, assim como toda logística das atividades científicas brasileiras.

A Marinha também conta com o apoio de aeronaves da Força Aérea Brasileira (FAB) (Figura 3A) para realização das chamadas Operações Antárticas (OPERANTAR). Os navios e aviões que participam das operações brasileiras partem da cidade chilena de 
Punta Arenas. Na Antártica é utilizado como suporte a pista de pouso da base aérea chilena Presidente Eduardo Frei Montalva (Figura 3A). A rotina nos aviões, navios e na base de pesquisa do Brasil também seguem diretrizes militares, exigindo hierarquia e disciplina.

\section{CLIMA E SEUS ELEMENTOS NA ANTÁRTICA.}

A maior parte das informações climáticas sobre a Antártica são coletadas nas várias estações de pesquisas existentes no continente. Além destas, existem vários sítios de monitoramento coletando dados constantemente através de sensores, os mais modernos instalados pela equipe do Terrantar/UFV, tem capacidade de acesso aos dados remotamente.

A Antártica apresenta condições climáticas mais extremas que o Ártico. O Hemisfério Sul apresenta uma distribuição diferente de terras e mares. Enquanto o Ártico é cercado por terras, a Antártica é uma grande massa terrestre (continente), cercado por um oceano (Figura 1). Porém as condições climáticas extremas da Antártica, como muitas vezes é repassado pela mídia, não retrata a realidade de todo o continente.

A Antártica não é homogênea e pode ser regionalizada, uma destas possibilidades é a compartimentação em Antártica Marítima (englobando a Península Antártica e arquipélagos como as Shetlands do Sul), Antártida Ocidental e Antártida Oriental, delimitadas pelas Montanhas Transantárticas (corta o continente na sua porção centro-sul) (Figura 4). A região com temperaturas mais amenas é a Antártica Marítima, temperatura média anual entre -10 e $-20{ }^{\circ} \mathrm{C}$ (CAMPBELL; CLARIDGE, 1987), as temperaturas podem chegar a ser positivas no verão e precipitações consideráveis podem cair em forma líquida. A Antártica é o continente mais frio da Terra, onde foi anotada a menor temperatura da história, medida na estação de pesquisa russa Vostok, na região Oriental (região mais fria do continente, onde situa-se o pólo sul), em 1983, quando registrou-se $-89,6^{\circ} \mathrm{C}$. 
Figura 4: Mapa de regionalização da Antártica (Marítima, Continental Ocidental e Continental Oriental), com algumas localidades e respectivas áreas livres de gelo.

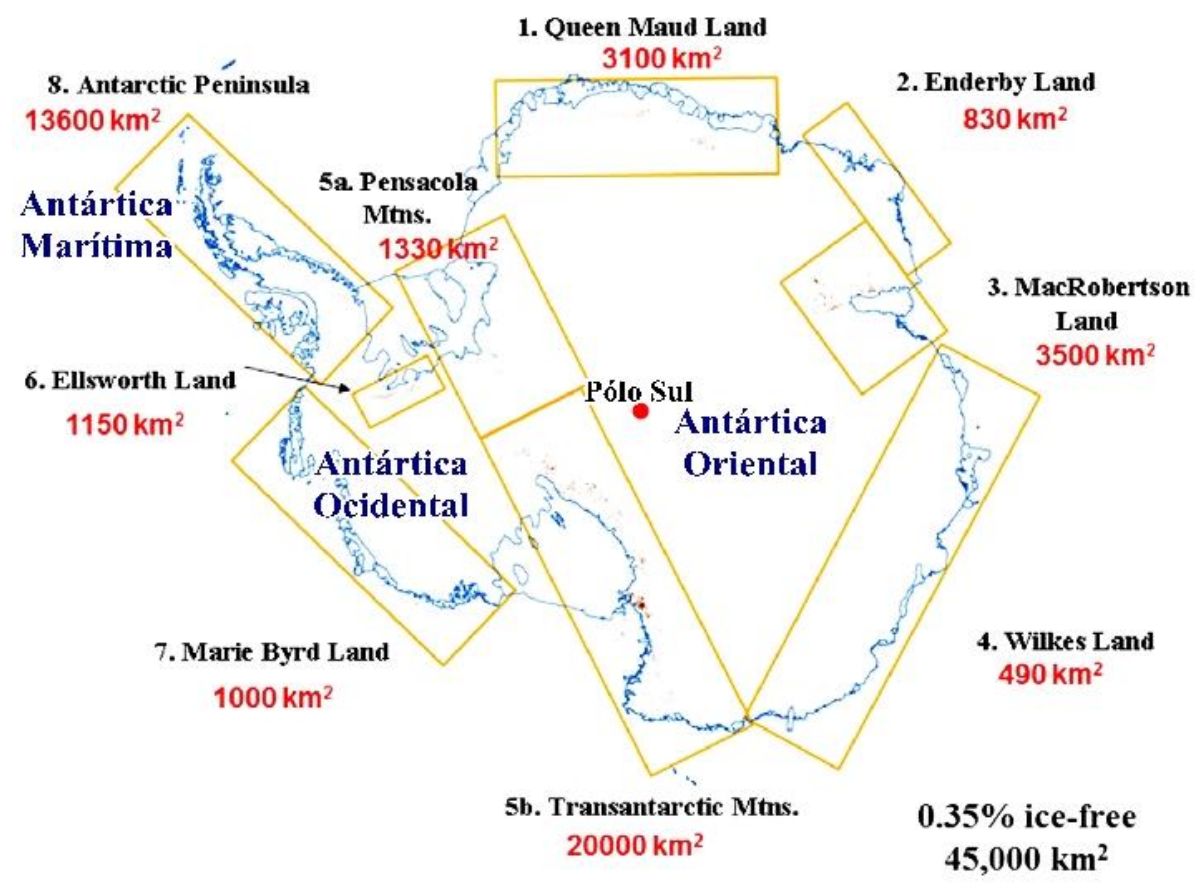

Fonte: adaptado de Bockheim et al. (2015).

A Antártica Oriental e grande parte da região Ocidental é um verdadeiro deserto gelado, com baixos índices de precipitação, apesar de ter muita água presente, esta permanece congelada (CAMPBELL; CLARIDGE, 1987). Estas geleiras possuem muitos gases, aprisionados, desta forma através da coleta de "testemunhos" (ice core), os gases podem ser analisados, o que permite que se faça uma reconstrução paleoambiental. Podem ser extraídas informações do clima pretérito, cada camada de gelo conta a história do período em que foi depositado, quanto mais profundo, mais antigo é o gelo. Impurezas no gelo também oferecem assinaturas, que permitem identificar ocorrências de erupções vulcânicas.

As baixas temperaturas na Antártica se devem em grande parte ao baixo nível de entrada de energia radiante no sistema Terra-atmosfera (CAMPBELL; CLARIDGE, 1987). Quanto maior a latitude, maior inclinação dos raios de sol que incidem sobre a superfície. No verão, a Antártica recebe cerca de $30 \%$ da radiação recebida pela região Equatorial (CAMPBELL; CLARIDGE, 1987). Nesta estação do ano, que a Antártica apresenta dias muito longos, quase $24 \mathrm{~h}$ de claridade, muito contrastante com a escuridão do inverno, quando o continente praticamente não recebe radiação solar (ANDRADE et 
al., 2018). Outro fator, determinante para as condições climáticas extremas é o elevado poder refletivo da neve e gelo (albedo).

A Antártica, também é tida como o continente mais ventoso. O padrão de ventos no continente é influenciado pelas geleiras colossais que recobrem o território. A perda de calor pela radiação da superfície das geleiras gera uma camada de ar muito frio. $\mathrm{O}$ fator altitude, em conjunto com camada de ar frio, oferece condições ideais para ocorrência dos Ventos Catabáticos (CAMPBELL; CLARIDGE, 1987). Estes, muito frios e densos, se movimentam com liberdade (praticamente sem obstáculos sobre as geleiras) e ao alcançarem as bordas, encontram um gradiente de elevação que oferece uma enorme energia gravitacional, assim os ventos descendem com muita força, causando nevascas e condições climáticas extremamente instáveis.

No contexto mundial, em que muito se fala em Mudanças Climáticas (naturais ou antrópicas) é válido mencionar um recorde, maior temperatura da história registrada na Antártica, medida pela equipe do Núcleo Terrantar/UFV, em 9 de fevereiro de 2020, registrou-se $+20,7^{\circ} \mathrm{C}$ na Ilha Seymour (Antártica Marítima). Este registro foi pontual e durou por pouco tempo, mas vale ressaltar que existe uma tendência de aquecimento, em destaque na Antártica Marítima, o que influencia o regime de precipitação e temperatura na América do Sul, incluindo o Brasil, principalmente as regiões Sul e Sudeste.

\section{GEOMORFOLOGIA E PAISAGENS SUI GENERIS.}

Os estudos geomorfológicos na Antártica podem ser divididos basicamente em dois grandes grupos: 1) Geomorfologia Glacial e 2) Geomorfologia Periglacial. A Geomorfologia Glacial estuda as formas de relevo associadas as dinâmicas das geleiras (glaciares). Glaciares são massas de neve recristalizadas, compactas suficientes para deformar a superfície, são dinâmicas e apresentam fluxo gravitacional sob seu próprio peso, assumindo uma variedade de formas que refletem a topografia e clima circundantes (COPLAND, 2013). Sua gênese se relaciona principalmente às altas latitudes (como Antártica e Ártico) e ambientes montanhosos (como Andes e Alpes).

Toda a água congelada na Terra constitui a criosfera (gelo e neve presente na atmosfera, lagos, rios, oceanos e sob a superfície). Só as geleiras constituem cerca de dois terços de toda água doce do planeta (HUGGETT, 2006). Atualmente, as geleiras cobrem 10\% da superfície terrestre (COPLAND, 2013) e o gelo marinho cobre cerca de 
$7 \%$ da superfície do oceano nos picos de inverno (HUGGETT, 2006). A maior parte do gelo glacial está confinado em altas latitudes (Antártica, Groenlândia e Ártico).

Ao contrário do que muitos imaginam as geleiras não são estáticas, elas se movimentam como rios, porém em velocidades muito baixas, podendo chegar a metros por ano. A movimentação destas massas de gelo tem grande capacidade de transporte, podendo mover grandes blocos rochosos. Desta forma, por onde as geleiras se movimentam as paisagens vão sendo moldadas e esculpidas. Vales que eram estreitos e fechados ("vales em V"), podem se alargar com o desgaste promovido pela passagem das geleiras e adquirir um formato típico dos ambientes glaciais ("vales em U").

As geleiras, também tem a característica de depositar todo material que ela transporta em uma zona de deposição à jusante (na sua frente), chamado de depósitos de morainas. Como as geleiras tem capacidade de transportar materiais de tamanhos diversos, é comum que nestes depósitos tenham-se materiais mal selecionados. Os glaciares também podem provocar significativa e extensa subsidência (afundamento) das massas terrestres continentais por ajuste isostático, exercendo expressivas mudanças paisagísticas (WRIGH et al., 2009).

Os estudos geomorfológicos, associados a ambientes glaciais, permitem que se faça uma reconstrução paleoambiental através das análises dos vestígios deixados na paisagem. Até mesmo o Brasil possui registros da ação de glaciares que existiram há milhões de anos atrás, pode-se citar as marcas de geleira neopaleozóicas que existem no sudeste brasileiro, como, por exemplo, na cidade de Salto-SP.

Além dos estudos das paisagens afetadas pelas geleiras na Antártica, também tem-se estudos que são realizados em áreas livres de geleiras, porém submetidas a condições de congelamento e descongelamento constante. Estas áreas são chamadas de Periglaciais. Ambientes periglaciais ocupam cerca de $20 \%$ da área continental do planeta (GUTIÉRREZ; GUTIÉRREZ, 2016). O termo “periglacial” foi utilizado pela primeira vez pelo geólogo Walery Von Lozinski, em 1909, para tratar das condições climáticas e geomorfológicas das zonas periféricas a geleiras pleistocênicas (GUTIERREZ, 2008).

Ambientes periglaciais, se caracterizam pelo predomínio de ciclos de congelamento e descongelamento, podendo existir permafrost e/ou terrenos permanentemente gelados (GUTIERREZ, 2008; FRENCH, 2007). Esta dinâmica promove modificações na paisagem. O permafrost é uma condição do solo, rocha ou sedimento, que permanece congelado por pelo menos 2 anos consecutivos. O permafrost 
é muito sensível às alterações climáticas, qualquer alteração pode promover o seu descongelamento e, consequentemente, acarreta na liberação de vários gases aprisionados nas camadas mais profundas, entre eles gases de efeito estufa (metano e dióxido de carbono). Em áreas com descongelamento do permafrost tem-se grande perca de volume, desta forma tem-se um processo de afundamento das superfícies (termocarste).

Estes ambientes geomórficos estão associados a processos e formas de relevo sob climas frios em altas latitudes e altitudes (BARSCH, 1993). Os processos e formas de relevo periglaciais, juntamente com a presença de permafrost, estão entre os elementos geomorfológicos mais relevantes na Antártica Marítima (LOPEZMARTINEZ et al., 2012) e nas cadeias montanhosas, como os Andes na América do Sul.

Os processos de congelamento e descongelamento influenciam na quebra e fraturamento das rochas (formas angulares), deslocamento de partículas e migração de água/gelo (MACHADO et al., 2019). A quebra pelo gelo e processos relacionados, são sistematicamente enfatizados, assim como sua responsabilidade na formação de uma vasta gama de formas de relevo (ANDRE, 2003). Esta dinâmica se deve a expansão da água ao congelar, aumentando seu volume em cerca de 9\% (FRENCH, 2007), o que promove aumento de pressão e, consequentemente, a quebra mecânica das rochas gerando clastos (fragmentos de rochas) angulares ou sua desintegração granular. Estes materiais, podem formar campos de blocos em superfícies planas ou acumulações de tálus (tipo de depósito com os fragmentos das rochas que vão sendo quebrados) em encostas (GUTIERREZ, 2008).

\section{SOLOS E PRESERVAÇÃO NA ANTÁRTICA.}

Nas áreas livres de gelo que se concentram as pesquisas sobre os solos (Pedologia) na Antártica (Figura 2). A importância destes estudos perpassam por objetivos distintos. Alguns estudos, sobre os solos, estão voltados para questões ambientais e contaminações. A maior parte das atividades humanas na Antártica ocorrem em áreas livres de gelo, nestas, as estações de pesquisas atraem grande fluxo de pesquisadores e visitantes, no curto período do verão austral (Figura 3). Apesar das atividades no continente serem regidas pelo Tratado Antártico (1959), o qual tem como um dos principais objetivos a preservação ecossistêmica, são identificados diversos 
impactos antrópicos. Nas áreas livres de gelo encontram-se locais de cabanas históricas e sítios biologicamente ricos, os quais são susceptíveis a impactos (O’NEILL; AISLABIE; BALKS, 2015).

Impactos antrópicos na Antártica, datam desde a chegada dos primeiros exploradores no final do século XIX, quando a busca por novas terras e a caça por baleias trouxe a construção das primeiras estruturas permanentes (O’NEILL; AISLABIE; BALKS, 2015). As grandes expedições lideradas por desbravadores como Borchgrevink, Scott, Shackleton, Mawson e Amundsen, deixaram registros arqueológicos como cabanas, instrumentos, objetos e os primeiros impactos humanos no continente (O’NEILL; AISLABIE; BALKS, 2015).

Apesar de ser o continente mais preservado do mundo, têm-se registros de impactos de diversos níveis, como distúrbios físicos (modificações paisagísticas devido à formação de trilhas ou estradas), mobilização do solo em que a perturbação da camada ativa resulta na degradação do permafrost, vazamento de substâncias estranhas (combustíveis e águas residuais), introdução de organismos estrangeiros (fauna e flora), entre outros (O’NEILL; AISLABIE; BALKS, 2015) (Figura 3). Solos da Antártica geralmente são pouco desenvolvidos, o material solto é muitas vezes coberto por uma fina camada protetora de cascalho e areia grosseira conhecida como pavimento desértico. A perturbação deste tende a favorecer processos erosivos e distúrbios na camada ativa e permafrost (O’NEILL; AISLABIE; BALKS, 2015).

Em 25 de fevereiro de 2012, um incêndio devastou cerca de $70 \%$ da base de pesquisa brasileira na Antártica, Estação Comandante Ferraz (EACF), localizada na Ilha Rei George (FIGURA 3D). Além da perda de vidas humanas (2 militares brasileiros), o desastre levou a um aumento da concentração de elementos tóxicos no solo como $\mathrm{Cu}, \mathrm{Pb}$ e Zn, os quais são prejudiciais para o ecossistema local (GUERRA et al., 2013). A nova EACF foi inaugurada em 15 de janeiro de 2020, mais segura, ampla e moderna, área de $4.500 \mathrm{~m}^{2}$ com setores privativos, área social, serviços, operação/manutenção, laboratórios e módulos isolados.

Além das questões ambientais, estudos com solos da Antártica desenvolvidos sobre situações extremas também são relevantes em função do conhecimento referente à gênese, fatores e processos em condições únicas (LOPES et al., 2019). Estas informações podem auxiliar em uma visão diferente do clima, material de origem, tempo 
e processos biológicos relacionados (CAMPBELL; CLARIDGE, 1987; LOPES et al., 2019).

Diferentemente do Ártico, onde tem-se como animal símbolo o urso polar, a Antártica tem como referência faunística os pinguins (Figura 3.E). Os ambientes colonizados por pinguins sofrem uma série de mudanças nas propriedades dos solos em decorrência do guano (excrementos de aves) e sua decomposição (TATUR; MYRCHA, 1984; MICHEL et al., 2006; SIMAS et al., 2007; SIMAS et al., 2015; SCHAEFER et al., 2017). Este material ornitogênico (do grego ornithos $=$ aves e genesis $=$ origem) acarreta na formação dos chamados solos ornitogênicos, frequentemente com alto teor de cascalho transportados pelas aves e identificado por outros indícios, como ossos, cascas de ovos e penas (IUSS WORKING GROUP WRB, 2014). Áreas com solos ornitogênicos constituem o local mais importante de sequestro de carbono na Antártica (SIMAS et al., 2007). Nestes ambientes, ricos em nutrientes, tem-se favorecimento ao crescimento da vegetação (TATUR; MYRCHA, 1984; MICHEL et al., 2006; SIMAS et al., 2007; SIMAS et al., 2015; DAHER et al., 2018).

Informações sobre os solos também auxiliam em estudos de interface, por exemplo, pesquisa recente na Antártica, na Ilha Deception, abordou sobre a diversidade e ecologia de fungos em solos sobre diferentes gradientes térmicos. Identificou-se fungos que sobrevivem em condições extremas, incluindo fungos causadores de doenças (Aspergilose, tipo de doença pulmonar) (FIGUEREDO et al., 2019). A presença de turistas na Antártica (Figura 3.C), em destaque indivíduos imune comprometidos e/ou idosos, pode ter risco à saúde (FIGUEREDO et al., 2019).

\section{CONSIDERAÇÕES FINAIS.}

A Antártica é um continente muito especial, seu valor científico se deve a diversos fatores: fauna e flora desenvolvida em condições extremas; geleiras que são colossais reservatórios de água doce e ainda possuem gases aprisionados que permitem que se faça uma reconstrução paleoambiental da Terra; relevos e solos que compõem paisagens únicas e com processos singulares, que permitem até mesmo que se façam comparações com as condições de outros planetas; clima extremo que caso seja alterado acarretará em influências na América do Sul.

Existem muitas questões geopolíticas envolvidas na Antártica e com o fim do Tratado Antártico em 2048, podem ocorrer muitos conflitos entre as potências mundiais 
e países mais próximos que já reivindicam territórios no continente desde o século XX. Espera-se que os países envolvidos cheguem a um consenso antes do fim da validade do Tratado e que as medidas sejam favoráveis à continuação da preservação deste grande laboratório natural.

Devido a todas peculiaridades, curiosidades e por ser um continente com condições extremas, longínquo e ainda com terras a serem desbravadas, o tema "Antártica" tem grande interesse e potencialidade de ser utilizado no processo de ensino/aprendizagem, principalmente nas aulas de Geografia, podendo atrair a atenção, despertar motivações e aguçar a curiosidade dos alunos.

\section{REFERÊNCIAS BIBLIOGRÁFICAS.}

ALMEIDA, I.C.C. et al. Active layer thermal regime at different vegetation covers at Lions Rump, King George Island, Maritime Antarctica. Geomorphology, 225, 36-46, 2014.

ANDRADE, I.O. et al. O Brasil na Antártica: A Importância científica e Geopolítica do Proantar no Entorno Estratégico Brasileiro. Brasília: IPEA, 2018.

ANDRE, M. F. Do periglacial landscapes evolve under periglacial conditions? Geomorphology, v. 52, n. 1-2, p. 149-164, 2003.

BARSCH, D. Periglacial geomorphology in the 21st century. Geomorphology, v. 7, n. 1-3, p. 141-163, 1993.

BOCKHEIM, J. G. Soil-Forming Factors in Antarctica. In: BOCKHEIM, J. G. (Ed.). . The soils of Antarctica. 1. ed. Switzerland: Springer International Publishing, 2015. p. $5-20$.

CAMPBELL, I. B.; CLARIDGE, G. G. C. Antarctica: soils, weathering processes and environment. p. 368pp, 1987.

COPLAND, L., Classification of ice masses. In: SHRODER, J., GIARDINO, R., HARBOR, J. (Eds.), Treatise on Geomorphology. Academic Press, San Diego, CA, vol. 8, Glacial and Periglacial Geomorphology, pp. 45-52, 2013.

DAHER, M. et al. Ornithogenic soils on basalts from maritime Antarctica. Catena, v. 173, n. March 2018, p. 367-374, 2019.

DELPUPO, C. S. et al. Soil formation in Seymour Island, Weddell Sea, Antarctica. Geomorphology, p. 1-13, 2014. 
FRANCELINO, M. R. et al. Geomorphology and soils distribution under paraglacial conditions in an ice-free area of Admiralty Bay, King George Island, Antarctica. Catena, v. 85, n. 3, p. 194-204, 2011.

FRENCH, H. M. The Periglacial Enviroment. 3. ed. Chichester: John Wiley \& Sons Ltd, 2007.

GANDRA, R.M. 2009. O Brasil e a Antártida: ciência e geopolítica. Geografias. Belo Horizonte 05(2) 65-74 julho-dezembro de 2009.

GUERRA, M. B. B. et al. Post-fire study of the Brazilian Scientific Antarctic Station: Toxic element contamination and potential mobility on the surrounding environment. Microchemical Journal, v. 110, p. 21-27, 2013.

GUTIERREZ, E. M. Geomorfología. Madrid: Pearson Educación, SA, 2008.

GUTIÉRREZ, F.; GUTIÉRREZ, M. Periglacial Landforms. Landforms of the Earth. 1. ed. [S.1.]: Springer International Publishing, 2016. p. 221-236.

HUGGETT, R. Glacial and Glaciofluvial Landscapes. Fundamentals of Geomorphology. 2. ed. [S.1.]: Routledge, 2006. p. 246-276.

IUSS WORKING GROUP WRB. World Reference Base for Soil Resources. International soil classification system for naming soils and creating legends for soil maps. Rome: World Soil Resources Reports No. 106. FAO, v.43, 2014.

LOPES, D.V. et al. Solos e Evolução da Paisagem em Ambiente Periglacial na Península Barton, Antártica Marítima. Geography Department University of São Paulo, v. 0, n. spe, p. 259, 27 jun. 2017.

LOPES, D.V. et al. Solos de basalto da Antártica: implicações paleoclimáticas ao longo de uma sequência climática. REDE - Revista Eletrônica do PRODEMA, Fortaleza, v. 13, n. 1, p. 7-18, dez. 2019. ISSN 1982-5528.

LOPEZ-MARTINEZ, J. et al. Periglacial processes and landforms in the South Shetland Islands (northern Antarctic Peninsula region). Geomorphology, v. 155-156, p. 62-79, 2012.

MACHADO, M. R. et al. Paisagens polares não glaciais (Proglacial, Paraglacial e Periglacial): Revisão de conceitos e contribuições da pesquisa pedogeomorfológica brasileira. Revista Brasileira de Geomorfologia, v. 20, n. 3, p. 603-622, 2019.

MICHEL, R.F.M. et al. Ornithogenic Gelisols (Cryosols) from maritime Antarctica; pedogenesis, vegetation, and carbon studies. Soil Science Society of America Journal, v. 70(4), n. October, p. 1370-1376, 2006.

O'NEILL, T. A.; AISLABIE, J.; BALKS, M. R. Human Impacts on Soils. In: BOCKHEIM, JAMES G. (Ed.). The soils of Antarctica. 1. ed. Switzerland: Springer International Publishing, 2015. p. 281-303. 
PEREIRA, T. T. C. et al. Genesis, mineralogy and ecological significance of ornithogenic soils from a semi-desert polar landscape at Hope Bay, Antarctic Peninsula. Geoderma, v. 209-210, p. 98-109, 2013.

SCHAEFER, C.E.G.R. et al. Penguin activity modify the thermal regime of active layer in Antarctica: a case study from Hope Bay. Catena, v. 149, p. 582-591, 2017.

SIMAS, F.N. et al. Ornithogenic cryosols from Maritime Antarctica: Phosphatization as a soil forming process. Geoderma, v. 138, n. 3-4, p. 191-203, 2007.

SIMAS, F.N. et al. Clay-sized minerals in permafrost-affected soils (Cryosols) from King George Island, Antarctica. Clays and Clay Minerals, v. 54, n. 6, p. 721-736, 2006.

SIMAS, F.N. et al. Soils of the South Orkney and South Shetland Islands, Antarctica. In: BOCKHEIM, J. G. (Ed.). . The soils of Antarctica. 1. ed. Switzerland: Springer International Publishing, 2015. p. 227-273.

SIMÕES. J.C., ARIGONY-NETO, J., BREMER, U.F. O uso de mapas antárticos em publicações. Pesquisa Antártica Brasileira, 4, 2004: p. 191-197.

SIMÕES. J.C. O ambiente antártico: domínio de extremos. In: Simões, J.C. et al. Antártica e as Mudanças Globais: um desafio para a humanidade. Série Sustentabilidade. São Paulo, Blucher, 2011. p. 15-27.

TATUR, A.; MYRCHA, A. Ornithogenic soils on King George Island, South Shetland Islands (Maritime Antarctic Zone). Polish Polar Research, v. 5, n. 1-2, p. 31-60, 1984.

WRIGHT, A.P. et al. Antarctica at the Last Glacial Maximum, deglaciation and the Holocene. In: FLORINDO F. AND SIEGERT, M. (Ed.) Antarctic Climate Evolution, Elsevier. pp. 531-570, 2009. 